\title{
STRATEGIC MEANING OF CULTURAL VALUES: A QUALITATIVE RESEARCH IN KAYSERI OIZ FURNITURE INDUSTRY
}

\author{
*Mehmet ERTEM (Orcid Id: 0000-0001-9350-4379) \\ *Izzet KILINC (Orcid Id: 0000-0002-6069-1291) \\ "Yozgat Bozok University \\ ${ }^{* *}$ Duzce University
}

\begin{abstract}
Although it's well-known that cultural values affect and shape the behaviors of managers as giving them measures for evaluating their managerial behaviors according to the society they live in, the characteristics of this relationship between cultural values and strategy is not fully understood yet. Thus, this paper aims to contribute to the existing literature as making effort to understand this relationship better. For this purpose, we aim to determine whether the strategists attribute strategic meanings to certain cultural values they brought from the society they live in. We gathered data through semistructured in-depth interviews conducted with 33 participants including business owners and top managers of 28 furniture manufacturing companies operating in Kayseri OIZ/Turkey. We analyzed the data with the method of "Conceptual Content Analysis" and determined that there are certain cultural values which were attributed strategic meaning by the strategists, such as honesty, helpfulness, and trustworthiness.
\end{abstract}

Keywords: Strategy, Cultural Values, Strategic Meaning, Qualitative Research

\section{INTRODUCTION}

Values have a wide range of meanings in the area of social sciences. Value is a root concept that is providing a theoretical base for explaining behaviors of individuals and social structures, together with the other basic concepts of social sciences such as attitudes, beliefs or assumptions (Bamberger 1986). Values are, with the most basic definition, abstract ideals which are providing standards to distinguish what is positive and/or good from what is negative and/or bad, to the society. (Schwartz \& Bilsky, 1987). Those ideals can shape the behaviors of individuals or guide them about how to behave in certain situations as providing behavioral standards. In short, values draw the border lines of the behavioral plane of a society. Naturally, this effect of values is operative in the area of management and organization too. We can say that, in management and organization area, almost all of the theories and models which are focusing on "behavior" or other related concepts have somehow, been paying regard to the effects of cultural values on human behavior. However, this interest of the area is rather shallow and it is mostly under general titles like "Cultural Effects" or just "Culture". In this context, we have to mention that the number of the studies focusing on the characteristics of the relationship between the values and management and more specifically between the values and strategic management is quite limited. Thus, this research study is focused on understanding the relationship between cultural values and strategy.

When looking at the studies focusing on the relations of cultural values and strategy, it is quite visible that they examine the subject mostly over the relations between organizational culture and strategic management. The other studies working the subject over social culture, with a wider perspective, seem to be mostly theoretical or empirical studies using just Hofstede's (1984) national culture dimensions (Hofstede, 1984). On the other hand, we also observed that the studies focusing on the effects of cultural values on strategic management processes examine the subject mostly over personal values of the strategists (top management, CEOs etc.) (Goelzer, 2003; Guth \& Tagiuri, 1965). Moreover, it's a wellknown fact that the personal values of business owners and top managers have a determinative position in organizational cultures, ways of doing business and strategic procedures in their companies (Smith \& Vecchio, 1993; Bamberger, 1986; Schein, 2004; Geletkanycz, 1997; Guth \& Tagiuri, 1965). In this regard, we don't think it will be wrong to think that cultural values directly or indirectly affect basic strategic processes like strategy formation and development, strategic decision-making, strategic thinking, strategic change. Consequently, it is natural and significant to think that strategists attach strategic 
meanings to the values they acquired from the society they live in. We also consider it valuable, from the aspect of the strategic management area, to make an effort to determine and understand which specific strategic meanings are attached to which specific cultural values.

\section{WHAT IS STRATEGY IN THE CONTEXT OF CULTURE}

Strategy is one of the multi-defined or not clearly defined concepts of social sciences. In the area of management and organization, the question "What is or isn't strategy?" is one of the basic questions which have been shaping the strategy schools ruling today's strategic management area (Mantere, 2013). Strategy is generally described in strategic management books as the following definition (Johnson, Scholes, \& Whittington, 2009):

"Strategy is the direction and scope of an organization over the long-term: which achieves advantage for the organization through its configuration of resources within a challenging environment, to meet the needs of markets and to fulfil stakeholder expectations."

As emphasized in the definition, strategy which is taking organization's and its shareholders' needs in the center, aims to obtain a competitive advantage through effectively using organization's resources and competencies in order to sustain its presence in long-term.

When looking at the schools of strategy, we can see that deeper and more sophisticated definitions take the place of shallow and general definitions of strategy. Mintzberg's (1979) ten different schools of strategy can be listed as follows (Mintzberg, 1979):

- The Design School

- The Planning School

- The Positioning School

- The Entrepreneurial School

- The Cognitive School
- The Learning School

- The Power School

- The Cultural School

- The Environmental School

- The Configuration School

Two of the most important schools of strategy are The Planning and The Learning schools. Because one of the most fundamental debates in the field of strategic management takes place between these two schools. This debate is about whether strategy is a deliberately formed plan or a course of action that is being spontaneously developed and can only be observed in the future after it occurred (Mintzberg, 1985). In fact, this debate is based on the attempts of answering one important question: "What is strategy?". This is an essential question for this study, which is mentioning "Strategic Meaning" in its main title. Because we can't decide what is "strategic meaning" and thus, whether a strategic meaning is attributed to a cultural value or not, without defining the terms of "strategy" and "strategic". In this context, we will try to examine different strategy definitions coming from different schools of strategy for being able to determine the main lines of "Strategic Meaning".

As stated earlier, there are many ideas and definitions about what strategy really is and how it operates. For example, the schools of design and planning see strategy as a process of intelligent design and planning in a controlled and formal manner (Ansoff, 1957). On the other hand, the Positioning School (Porter, 1998), which basically does not reject the assumptions of the school of design and planning, defines an area (the industry) in which the basic elements that are effective in the strategy formation process take place and it defines strategy as determining the right position for the organization in this area. The Entrepreneurial School, which has a different point of view from these schools, considers the strategy as a general direction that exists in the personal mind sets of entrepreneurs/leaders and it is being shaped according to their own experiences and intuitions (Schumpeter, 1934). Another view which evaluates strategy depending on the leader is the Cognitive School of Strategy. The difference between this school and the Entrepreneurial School is that it evaluates the strategy based on the cognitive aspect of the leader's mind, not the leader's subjective qualities like intuitions and experience. The Cognitive School considers the strategy as a concept developing over the elements of the leader's cognition, such as schemas, maps, perceptions, and interpretations. The Learning School, which evaluates strategy from another point of view, considers the leader of an organization as the organizer of strategy formation and implementation processes. The learning school sees the strategy as a natural result of an unintended (not planned), spontaneous learning process that encompasses the whole organization (Mintzberg, 1979). In 
this mechanism, organizations experience a variety of situations that require strategic decisions throughout their life cycle, and they become more prepared for further strategic decision situations coming in their future business lives as learning from the results of these strategic decision situations they experienced. As another approach, the Power School considers strategy as a persuasion and bargain process which is being shaped by the power-oriented political relations that occur inside and outside the organization (Pfeffer \& Salancik, 1978; Hickson \& Hinnings, 1971). The environmental school, on the other hand, considers the organization's environment as the leading factor of its strategy-making processes. According to this approach, organizations make their strategies in order to accord with their environments (Selznick, 1957; Hannan \& Freeman, 1977). The configuration school relates the strategy to the different structural phases that organizations go through in their life courses. (Miller \& P.H.Friesen, 1980). The last and most important (for this study) school of strategy is the cultural school. This school focuses on the relations of culture and strategy. The cultural school, which regards strategy as a shared view that is based on the common values and beliefs within the organization (Hedberg \& Jonsson, 1977), considers the process of bringing a strategy into existence as a process of social interaction.

According to the previous definitions and approaches trying to explain strategy and different strategic processes, we can say that strategy is a decision process which is related to both internal and external environments of an organization and this process aims to align with the environment through allocating and using the organization's own resources and competencies, in an effective and productive manner. For organizations, the desired outcome of this decision is gaining a sustainable competitive advantage over their rivals and by this means, granting to conduct their presence in the long-run. In short, a strategy is a process and as a result of this process, top managers/strategists mostly face a "strategic" decision situation. Scholes and Whittington (2009) list the characteristics of a strategic decision situation as follows: (Johnson, Scholes, \& Whittington, 2009, p. 2-3):

- It relates to the long-term orientations of organizations.

- It relates to gaining competitive advantage.

- It relates to aligning with the business environment.

- It is about the resources and competencies of the organization.

- It relates to the values and expectations of the people (employees, customers, suppliers etc.) inside and outside the organization.

All the characteristics of the strategic decision processes mentioned above aim to sustain an organization's long-term presence through gaining and sustaining competitive advantage. The last one of these characteristics and the cultural school of strategy we mentioned before, constitute an intersection point in between strategy (strategic decisions) and culture. As a result, we think that talking about the values and expectations of people inside and outside the organization can be considered as a direct reference to culture and cultural values.

\section{Cultural Values and Strategists}

Culture, which can be defined as a key concept for social sciences like sociology, anthropology, psychology, and social psychology, has started to attract the attention of the management and organization field at the end of 70's and since then a wide body of literature has been formed under the title of "Organizational Culture" (Lewis, 1996-a; Lewis, 1996-b). The etymological roots of the word "culture" come from the Latin word of "Cultura". On the other hand, Morgan (1986) refers to the idea that the word culture is related to the word "to cultivate" in order to emphasize the cultivable characteristics of culture (Morgan, 1986, 609).

Although culture is one of the most basic concepts in social sciences, it is far from having a single definition that everyone agrees about. There are many different definitions of culture. For example, Geertz (1973) defines culture as a pattern of meanings which comes from history and embodied in symbols. According to him, culture is a body of concepts that is inherited from the previous generations and individuals reflect this body of shared concepts in different symbolic forms like communicating, developing their knowledge about life and shaping their attitudes toward life (Geertz, 1973; Morgan, 
1986). Hofstede (1984), defines culture as a mental program that distinguishes the members of a society or a group from the others. For him, culture consists of established thinking patterns that take place in people's minds and it keeps passing on from generation to generation. These shared patterns of thinking become evident in the institutions and tangible products of societies (Hofstede, 1984, p. 82). On the other hand, Pettigrew (1979), who construes culture in terms of values and beliefs, defines the concept as "a system of open and collective values that exist in a particular group at a given time that helps people in the society to understand their own situation". Moreover, this system of values has a dominant effect on the behaviors of the people who are embracing it. (Pettigrew, 1979, p. 574-577). One of the common features of these definitions is the emphasis on "shared values" (Golden, 1992, p. 2).

The values take place in the middle layer(s) of the multi-layered structure of culture (Schein, 2004). Because of this position in the cultural structure, they seem to be one of the most easily observable components of culture and yet they provide sufficient information for observers about the depths of the phenomenon. Values also form the core of culture along with other shared elements like norms and basic assumptions. According to the related literature, the values can be described as concepts or beliefs which (a) are related to the desired final states or behaviors, (b) exceed specific situations and incidents, (c) guide the selection and evaluation of behaviors and events, (d) can be sorted by their relative importances (Schwartz \& Bilsky, 1987, p. 55).

The individuals who adopted a culture, take and internalize the values which reside in the core of that culture through their own psychological processes. Those internalized values shape and determine the behaviors of these individuals (Kroeber \& Kluckhohn, 1952). In other words, the cultural values that are owned by a society shape the behaviors of that society's members through the value judgments that are based on these cultural values. These value judgments determine behavioral borderlines like good-bad, beautiful-ugly or right-wrong behaviors (Schwartz \& Bilsky, 1987; Kroeber \& Kluckhohn, 1952). Behind these borders lies an area of culturally which we can define as a "Safe Behavioral Zone". For members of a certain society, staying in this zone with their behaviors means gaining the approval and acceptance of the society and staying out of it can cause them to be or to feel excluded from it. On the other hand, the individuals stepping out of the safe zone may experience some negative outputs like a real-ideal conflict (such as Horney's (1994) "Real-Ideal Personality" conflict (Horney, 1994)) in their personal psychologies, because staying in the borders means to comply with the moral or cultural values they accepted and labeled as "good and ideal" and staying out of the borders would mean showing behaviors, in their personal reality, which are not good or ideal and this inner conflict can cause pain (Ertem \& Kılınç, 2017; Horney, 1994). Individuals can decide to consider the cultural values important and stay in this safe zone for two different reasons. Firstly, they may be willing to avoid possible negative outcomes (such as being excluded from the society) or to obtain possible positive outcomes (such as gaining the society's acceptance) as caring about the cultural values (Instrumental Value (Bradley, 1998)). For an individual, behaving in this fashion refers to adopting the instrumental value of cultural values. Secondly, individuals can decide to stay in the safe zone just because they believe that those cultural values are valuable in themselves (Intrinsic Value (Harman, 1967: 796)) without any instrumental value.

On the other hand, it is a well-known fact that the personal value set of a top-level manager significantly affects the way he/she do business (Guth \& Tagiuri, 1965; Franwick, Ward, Hutt, \& Reingen, 1994; Bamberger, 1986; Watson, 2003). This effect can reveal itself in on different grounds such as leadership styles, organizational activities and strategic or tactic decision processes (Bock, Opsahl, George, \& Gann, 2011; Bettenhausen \& Murnighan, 1985; Watson, 2003). At this point, we have to say that the business owners and top-level managers are social individuals and their personal values have been shaped under the effects of their own society's cultural values, beliefs and basic assumptions (Schein, 2004).

The concepts of culture and strategy often come across in several studies, in the field of strategic management. For instance, one of the ten strategy schools of Mintzberg (1979) takes the name "Cultural School" and mentions that strategy is almost merely culture (Mintzberg, 1979). On the other hand, Barney (1986) claims that culture has a significant role in gaining and sustaining competitive advantage as an organizational resource (Barney, 1986). According to Weick (1979), some definitions of (organizational) culture and strategy are quite similar to each other so that you can even write these words in each other's place in their definitions and nobody can tell the difference (Weick, 1979). However, this close relationship in the literature is valid for only the relationship of organizational culture and strategy. When it comes to the relationship between strategic management and social culture (the wider meaning of 
culture containing organizational culture too), it is difficult to find numerous studies focusing on this relationship in the literature.

Schein (2004) points out that the cultural values and beliefs of an organization's founder adopted from his/her own society, is the initiator of that organization's culture (Schein, 2004). Therefore, we can say that the cultural values and beliefs of business owners and top managers directly and/or indirectly affect their ways of doing business such as conducting interpersonal relations, strategic thinking, and performing managerial practices. (Badr, Gray, \& Kedia, 1982; Franwick, Ward, Hutt, \& Reingen, 1994; Bock, Opsahl, George, \& Gann, 2011; Bamberger, 1986). When we look at the few studies focusing on the relationship between culture and strategy, we can easily see that they examined the subject under two main limitations. The first limitation is narrowing the meaning range of the concept culture down to the organizational culture (Giberson, ve diğerleri, 2009; Smith \& Vecchio, 1993). Secondly, even if they do not limit their perspective with looking only to organizational culture, they study the subject with merely Hofstede's (1994) "Dimensions of National Cultures" scale and they adopt quantitative methods only (Geletkanycz, 1997; Martinsons \& Westwood, 1997; Lu, Rose, \& Blodgett, 1999; Harris \& Ghauri, 2000). We think that studying this subject under such limitations is an obstacle to understand it better and deeper. The reason for this is focusing only on organizational culture and values, makes it almost impossible to understand how social culture and values, which are also the roots of the organizational culture and values too (Cole, 1959; Weick, 1979), relate to the strategy and strategists. In this sense, during the next part of the study; we will try to understand, through interpreting qualitative research data, that what kind of strategic meanings the strategists attribute to which values they adopted from the culture of the society they live in.

\section{RESEARCH METHODOLOGY}

This research study has an interpretive and qualitative point of view which is in line with the subject and the aims of the study. In this context, the conceptual content analysis method has been used as the main research method. The population of the research consists of the business owners and top managers of (more than) 500 companies operating in Kayseri Organized Industrial Zone (OIZ) - Furniture Industry. The sampling method of the study can be characterized as "Snowball Sampling" which is one of the judgmental sampling methods.

We gathered data from 28 different companies and we judgmentally classified them as small (Employees $<100)$, medium $(100-200$ Employees) and large (Employees $>100)$ companies. According to this classification, we gathered the data from 4 large, 13 medium and 11 small companies. We interviewed 33 business owners and top managers during the field research period (04.11.2015-30.12.2015) and each of the interviews has taken times between 22-95 minutes.

\section{Qualitative Assumptions of the Study}

This qualitative and interpretive study is based on two main assumptions. Firstly, the reality surrounding the individuals in society and/or organizations is being interactively shaped/created by them. Secondly, these individuals collectively and interactively shape the meaning frames and references within the social structure they live in (Neuman, 2014; Weick, 1979; Berger \& Luckmann, 1991).

\section{Aims and Contributions of the Study}

The aim of this research study is to determine whether there are some specific cultural values which have been attributed strategic meaning by the business strategists. If there are such cultural values which have strategic meanings according to the participant strategists, determining and understanding what kind of strategic meanings these cultural values have in the research field is the secondary aim of this study.

As we emphasized before, it is not easy to find many qualitative studies focusing on the relationship between strategy and cultural values and the most important quality of this this study is its qualitative nature. We expect this study to make three main contributions to the literature as interpretively focusing on the culture-strategy relationship: (1) better understanding the qualities of cultural values-strategy relationship, (2) helping to better understand the processes of strategy formation and application under the effects of culture and, finally (3) contributing with qualitative data and analysis to the recently emerging field of Behavioral Strategy. 


\section{Research Strategy}

As mentioned before, the main method for collecting data in the study is semi-structured in-depth interviews. We conducted the interviews ourselves in the participants' own working places in order to observe their working environments too. We interviewed the participants face to face and we carried out the interview procedure in three stages. The first step is the stage of acquaintance in which we tried to learn about personal information of the participants. In the second stage, we briefly explained to them what is meant by cultural values and beliefs in this study. Then, we attempted to learn and understand the basic cultural values affecting the way the participant strategists do business. In the third and final stage, the participants were given basic information on strategy, strategic aims and strategic decisions. Then we asked them to tell an important strategic decision they made in the last 2-3 years' history of their businesses.

We tried to apply triangulation procedures for increasing the trustworthiness of the study in every possible step of the research process (Brink, 1993; Pitney \& Parker, 2009; Klenke, 2008). Firstly, we benefited not only the data coming from the interviews but also the data coming from the field observations and memos, in the analyze process.

Table 1: Applications Of Triangulation In The Research Process

\begin{tabular}{ll}
\multicolumn{1}{c}{ The Research Stages Triangulated } & \multicolumn{1}{c}{ Triangulation Applications Conducted } \\
\hline Preparing the Conceptual Framework & $\begin{array}{l}\text { The conceptual framework has been formed as } \\
\text { discussing with different academics from } \\
\text { different areas of the social sciences. }\end{array}$ \\
\hline Gathering Data and Transcription & $\begin{array}{l}\text { We gathered field notes and observation notes } \\
\text { from the field. }\end{array}$ \\
\hline Coding Analysis & $\begin{array}{l}\text { We used Isabella's (1990) coding reliability } \\
\text { application. }\end{array}$ \\
\hline Conceptualization & $\begin{array}{l}\text { Final conceptualization has been formed } \\
\text { according to the meetings with some of the } \\
\text { participants and academics. }\end{array}$ \\
\hline
\end{tabular}

On the other hand, we have had the help of a four-membered transcription team which consists of graduate students and research assistants in order to triangulate the transcription process of the interviews. Finally, we modified and used Isabella's (1990) coding reliability application for the reliability of the coding analysis procedure (Isabella, 1990, p. 13).

\section{Coding Procedures}

In this study, we applied a three-staged coding process: (1) open coding, (2) axial coding and (3) coding to conceptualize (Charmaz, 2006; Strauss, 2003). In the stage of open coding, we coded the expressions that refer directly to cultural values and beliefs. In the stage of axial coding, we grouped the cultural values and management practices which have been coded in detail before, under the titles of the main value groups. Finally, we re-coded the previously coded expressions referring to both "cultural values" and "strategic meanings and expectations" under the title of "The Cultural Values Which Have Been Given Strategic Meaning" and formed "Table 1" as a result of this last coding procedure.

\section{Background of the Study and the Position of the Researchers}

Kayseri city is geographically in the Central Anatolia region of Turkey. The city has a significant national and international reputation as a conservative (Islamic-oriented) trade and industry city. People who are form Kayseri is well-known for their remarkable trading and bargaining skills with their conservative (Islamic-oriented) way of life by the business world and the international press (Bilefsky, 2006; Lodhi, 2006). Additionally, Kayseri is also known as an exporting city (mostly furniture and steel doors) in Turkey (KAYSO, 2019). On the other hand, the furniture industry is regarded as a labor-intensive sector due to the certain features of furniture and subsidiaries manufacturing business (Erkekoğlu, Kıliçarslan, \& Göknar, 2014). In this context, we observed Kayseri OIZ furniture industry as a conservative (traditions and family relations) and relatively religious (from the aspect of Islamic values and practices) socio- 
economic structure. In this social environment, businessmen/women evaluate each other not only according to the certain financial indicators or common trading histories between them but also to the references of family relations and their acquaintances. Consequently, it was vital that we should use the same kind of family and acquaintance connections in order to reach the interviewees and to get their consents.

One of the researchers who conducted this study (Dr. Mehmet Ertem) is originally from Kayseri and completed most of his education life in this city. Moreover, he also worked in a furniture subsidiaries company as a foreign trade representative. Thus, it can be said that he is familiar with the target industry and social structure. On the other hand, the researcher has close relatives who are furniture business owners in Kayseri OIZ. Additionally, the researcher's (Dr. Ertem) academic familiarity with the research field comes from his experience of finishing the field survey of his Master Thesis (2011) in Kayseri OIZ furniture industry.

\section{INTERPRETATIONS OF THE DATA}

As a result of the coding procedure, it is determined that the interviewed strategists have been attributed strategic meanings to many different cultural values. Those values are as follows:

- Honesty

- Helpfulness

- Sincerity

- Being Principled

- Considering the Intrinsic Value of Culture
- Competitiveness

- Leadership as Guidance

- Quick Decision Making

- Adaptability

- Managing Risks, Acting with Deliberation

The list above includes not only cultural values but also some important organizational values and management practices. This is because it is observed that the participants have evaluated some specific organizational values and managerial practices in terms of the values of their society's culture. Thus, the values and practices above and the strategic meanings attributed to them by the participant strategists will be examined during the following sections of the study, in detail.

\section{Honesty}

The meaning of honesty for the participant strategists has been shaped by their aim of maintaining their organization's long-term presence. The participants believe that behaving honestly in business life serves the aim of long-term organizational sustainability. In other words, they believe that they can give trust to their customers and suppliers as behaving honestly in their business relationships with them.

Ours is a family business. The most important thing for us is honesty. We also have good relations with other companies. These good relations bring many positive things to us. In both long-term and short-term... (...) In the long run, humans... human relations... The people who know us become good references for us. In the following stages of our business, it provides us great convenience while working with other companies. In the short run, for example; even when we have an impossible thing to do with them, they help us and our job gets done immediately.

We determined that the participants consider that such a reputation which comes from their honesty will have consequences such as running the interpersonal relations and the functional activities within the organization more smoothly and establishing new and better business relationships with their existing customers and suppliers.

Honesty stands out as the value that is most emphasized by the participants. In fact, honesty itself is defined as a kind of capital. This concept of capital here gains its meaning with the Islamic concept of "Bereket (The plentifulness which comes with the blessings of Allah)".

Nothing happens without honesty... Our ancestors don't waste their words... They said, "honesty itself is capital". Without honesty, without the values of halal and haram, without having respect for the rights of your (business) partners, the concept we called "Bereket" remains disabled here. I mean, even if you earn 50.000 Liras this month, next month you lose it and 
additionally you have a debt of 50.000. Then you do not understand how it happens... This 50.000 goes and a debt of 50.000 comes. In a company which has "bereket", even if you earn just $10.000 /$ month, you can save money and make your capital bigger.

The participants believe that when they behave honestly Allah will bless their company and business transactions with "bereket". As a result of this blessing with bereket, they will be able to run their business smoothly and they can genuinely benefit from what they earn, even if they do not earn much. In other words, they choose to make an acceptable amount of money (Satisficing) with bereket over earning more and more each and every time (Maximizing).

\section{Helpfulness}

Helpfulness is one of the cultural values which are attributed similar strategic meanings to honesty, by the participant strategists. The strategic meaning here is developing long-term and trust-based relationships with customers and/or suppliers as helping them at certain pointsof their business lives. The quoted expression below points directly to this situation.

"I think this is one of the reasons why we have been holding in Kayseri for many years. We are keeping our promises and we help our suppliers from time to time. For example, I go to exhibitions or fairs with them to help. Even if those fairs are nothing related to my business, I sometimes go with them to help."

We think that the helping behavior of the participant here comes from both a feeling of responsibility to the suppliers whom he has a personal history with and, more dominantly, a feeling of sustaining a longterm and un-problematic business relationship with his suppliers. We can clearly see here that the participant strategist attributes a strategic meaning to helpfulness.

\section{Sincerity, Principlism and Considering the Intrinsic Value of Culture}

In the minds of participant strategists, the values of sincerity and principlism seem to be a set of values. This set of values is a structure consists of these two values and it is based on believing the intrinsic values of the cultural values. Thus, we examine them under the same title with the concept of intrinsic value. For the participants, sincerity takes two different forms: the first one is the sincerity against cultural values (attributing intrinsic value to them genuinely) and the second one points at the sincerity in interpersonal relations. The expression below belongs to a participant who is evaluating the role of sincerity in organizational context in terms of the advice he had taken from his mentor when he was younger.

Yes, we never close the doors of our offices. One of our older brothers (not family, an older person whom he respects very much) says this... He worked as a marketing manager for more than 13 years in a very big furniture company. He had a saying... I never forget his saying... We had long conversations with him on those days... He said once... Companies can grow bigger and bigger... They can become larger, they can become stock companies, holdings may be... maybe international they become... But if you close the doors in a company (closing the doors of the rooms in the company) it means the sincerity is limited by the doors... for both managers and lower level employees... He told me this... and it touched me..."

He tells here that the lack of sincerity can cause a distortive effect on both the relations between employees and higher levels and the relations within the top managerial level and this situation explicitly means having problems with conducting (strategic or tactical level) organizational processes. From this point of view, we can observe how valuable sincerity is, in terms of organizational sustainability.

Expressions referring to the sincerity in the external relations with customers and suppliers have also taken place in the data. For example, the expression below belongs to a participant who believes the importance of being sincere towards his customers. He is willing to be sincere to his customers according to the advice of his father and he believes that if he does not behave them sincerely, this will harm his business.

"The most important advice of my father to me is sincerity/genuineness. Sincerity in customer relations, sincerity in business transactions... (...) It means... Not sauciness or levity... But being 
genuine, being sincere to them while communicating with them. If it is not sincere, it is pretended... and being pretended in the relations makes us concede a goal (using a football/soccer term) in the long run."

At this point, we have to mention that, the sincerity of the relationship between individuals and the value of sincerity itself take place as a subject which is emphasized by the participants in the data. In other words, a strategist should see sincerity and also the other values like honesty or helpfulness as principles which have intrinsic value in themselves and he/she should behave in a principled fashion as a business person. The expression below reflects this kind of state of mind.

Firm $X$ is an ideal firm for me. A firm which has principles... It means they do not cheat people and they do not let anyone cheat them. There is a saying "Being a man like a (decent) man"... They are like that... They make you say "Yes that's how decent businessmen should behave! That's the way of doing proper business!". I mean they are not like market-oriented businessmen... They have principles... They have a philosophy... a way of thinking.... They have measures other than the market circumstances... They have serious reference points... I mean their point of view is not mere profit-oriented but human-oriented..."

In addition to its intrinsic values, the participant believes that having a principled stance in business activities has an instrumental value too, as facilitating to reach the basic goals of doing business like making profit.

"I mean, if you ask the man (he refers to an organizational customer he has met before) why do you buy the goods of this firm? I mean if I reached to all of my customers and ask them why they prefered us to do business. They would say "They are light-handed (a Turkish trade idiom, means if you buy from them you won't have problems with the goods you bought, from all aspects) ... They are principled... They follow up their goods after selling us...

Here the expression "following up" refers to a proper after-sale support and being easy to communicate even after the sale. On this context, it is said here that having a principle to provide after-sales support no matter what, is a reason for a company to be preferred over its rivals.

\section{Competitiveness}

Other than the cultural values mentioned before, competitiveness or (with one of the participants' own expression) "the feeling of being in a race" also takes place in the data as a value which has been attributed strategic meaning. The participants construe competitiveness and the feeling of being in a race with others as values that help their firms to renew themselves against the rapid change in the market and to keep up with their rivals. In here, attributing such importance to the competitiveness from the aspect of its instrumental value is an approach which is compatible with the related literature. The expressions below point at this particular meaning attributed to the value of competitiveness.

"For example, I never want to bring this company down. I never want this company to become a headache for the boss as an ambitionless, unchanging/stable, status quo supporter firm among other companies of the world. This one is a competitive company too. This is one of the most competitive companies of the holding group. I want this company to make efforts for constantly growing and developing. Because succeeding is like swimming against the current. If you stop renewing yourself, you drop behind because you are swimming against the current. You should be seeking constantly, making continuous efforts in order to keep your position and go further. If you do not keep up with the innovations and the change in the market, it means you slip down to the bottom."

Conversely, we came across with expressions which were giving a negative meaning to the value of competitiveness, in the data. Those expressions emphasize the importance and virtuousness of racing or competing not with others but yourself. The expression below belongs to a participant high-level manager and includes his thoughts about the business owners of the company he works for.

... Moreover, they race/compete with no one but themselves. This is very important. I've seen this in other firms I worked, it is very important. Somebody does that, somebody does this... They don't care what others do. Yes, they look at the outside but just for checking themselves, not for forming their business according to them. 


\title{
Leadership as Guidance, Quick Decision Making and Adaptability
}

The strategists who have contributed to the research, attribute strategic meanings to some values and practices for the purpose of gaining sustainable competitive advantage in the market. Those values and practices can be summed up as follows:
- Leadership as Guidance
- Quick Decision Making
- Adaptability

The participants who are natural leaders of their companies give a strategic meaning to the guidance role of leadership. The participant below defines his role in the company with a metaphor: "Navigation Device". He says he is a navigation device guiding his organization to adapt to its competitive environment and to conduct the complex organizational activities and processes correctly and rapidly.

\begin{abstract}
"In fact, my basic responsibility is to set a system which is working smoothly and to change and adjust it when necessary. Additionally, to observe the suitability of the changes and adjustments made and correctly locating the decisions I made for these changes and adjustments, in the system. For example, I need to change and modify this system when the circumstances of the competition change. I need to stimulate this system when a significant change occurs in our customer profiles, employee portfolios, needs or perceptions of our customers or in our legal environment. (...) Basically, I consider myself not as someone behind the wheel but a navigation device. There is a location to arrive and I tell where to turn right or left and which is the right direction. I give feedback about the righteous direction but there are other people behind the wheel."
\end{abstract}

In other respects, the participants mentioned in the data that some important situations including conflicts between the partners or lack of team spirit in superior-subordinate relationships might prevent the company to reach its goals as causing results like "Strategic Blindness" or not being able to keep up with the change. The following expression is the last part of a real story shared by a participant strategist. In the story, the partners of a company could not see their company is "sinking" just because of the conflict between them.

"You know X firm... It's a modular furniture company. They are one of the oldest firms in the market. It was impossible for them to go down... They had profit margins like \%50 or more maybe. But a clash between the partners... The one who is responsible with the finance department says something, the one responsible with the manufacturing department says another thing and they argue... And so on... Because of the heavy psychological atmosphere of the clash, they were not able to see their firm was going down. This kind of problems occur..."

The strategists consider the lack of ability to make quick and accurate decisions, and thus not being able to keep up with the rapid changes in the environment as a major strategic threat like a situation of inconsistency between partners.

"The problem of rapidly moving companies is failing to adapt to the change in their environment and this is what shortens the lifetimes of Kayserian companies. For example, I know this very well that If there is someone in my company who is distorting the adaptation ability of us, I must either educate and correct him/her or send him/her out of the company. Now the situation is clear and certain like this. Because we don't have enough time. We cannot spend 3 or 5 years for dealing this."

\section{Managing Risks and Acting with Deliberation}

The participants attribute great importance to certain skills (such as adaptability, quickness, and accuracy in decision-making) and aims (the strategic ones such as growth and gaining sustainable competitive advantage). However, for most of them, giving importance to these skills and aims never means recklessly pursuing them without taking the possible risks into consideration. In this context, we observed (significant numbers of) expressions in the data which are emphasizing the importance of acting with deliberation or managing risks. These expressions which are mostly in the form of idioms or advice of elders as follows: 
- Do not put all your eggs in just one basket.

- Do not dive in the water if you do not see its bottom.
- Don't be greedy, do business comfortably.

- If you have 10 Liras use just 5 Liras for doing business

The first advice would sound familiar to anyone who has taken Finance 101. It is the first and most important principle of risk management. The interesting point here is the participant below refers to this principle as a piece of advice he took from his elders during his childhood.

“(...) I always tell this to people... They (our elders) taught us this in our childhood that you shouldn't put all your eggs in one basket. If you put your eggs in more than one baskets, you can save at least some of your eggs in case of an accident. This is how we grow up in Kayseri."

The same participant mentions the second expression as another advice he took from his elders in his childhood. He also associates this advice with Kayseri's geographical location.

"When we were growing... Our elders taught us when we were children. They said: "Do not dive in the water if you don't see its bottom! Keep your feet on the ground". Even now... I am an adult now and I still do not dive in the water deeper than my height. Maybe it's related to the geographical location of Kayseri. We do not have a sea in here. So... We cannot swim well... But maybe it is about our elders... They wanted us to be safe from all aspects..."

We also observed that some of the participant strategists negatively interpret the state of ambitiously pursuing goals for gaining more and more each time. The following expression states such an interpretation.

"In this company, we do not try to sell our goods to everyone possible. We do not try to conquer the entire market. We do not try to make "too much money". Our principle is to work with honest firms who are keeping their words and doing quality work. We have 10-15 customers who have these qualities. We work just with them. If their need increases, we increase our production. If their need decreases, we decrease production. We work according to them. We work with reputable customers so that we don't have problems with business transactions. ... And we keep our promises too... If it is necessary, we work with our employees to help them but we finish our work at the right time. We have a clean business... We do business smoothly. This point is where our decades of business experience brought us."

In short, the idea here is "being overambitious brings harm to the business". Along with this idea, the last advice from the list emphasizes the necessity of regarding a harmony between the capital and the size of the venture.

"Those who are "hunting birds as using other people's stones (Turkish idiom means: doing business without a strong capital as using checks or other legal paper instruments)", who are doing 10 Turkish Liras business even if they have even less than 5 Turkish Liras in their pockets... They are suffering from bad surprises... But the ones like E... Furniture Company... Those who have strong operational capital... Those who are doing 5 Liras business even if they have 10 Liras in their pockets... They do not face bad surprises... They are more steady and strong... They live longer in this business arena... Because Turkiye is a critical country with many economic crises. There are problematic areas around us... You know... The Middle East... etc."

According to the participant strategist, companies and business people should use half of the capital they posses and keep half of it as a precaution for bad surprises. Thus, they would be able to sustain their presence in the business arena for a long time period.

\section{CONCLUSION}

Consequently, we determined that the participant strategists attribute strategic meanings to specific cultural (and/or organizational) values and managerial practices. Those values and practices can be classified under three main titles: 
According to the strategists participated in our research study, strategic sustainability means sustaining the presence of the firm in long-term. This term also includes developing, planning and applying the activities that bring strategic sustainability to the company. In this context, the participant strategists think that they can obtain strategic sustainability as developing closer and trust-based business relations with their customers and suppliers. They believe they should genuinely possess and exhibit some important values like honesty, sincerity, trustability, and helpfulness in order to develop such kind of a close relationship with their customers and suppliers.

The second title above represents "Strategic Competitive Advantage". According to our research field, strategic competitive advantage means surpassing their rivals in the long-run. In the context of this title, the participant strategists attribute strategic meaning to the values and practices of competitiveness, quick decision-making, leadership as guidance and adaptability. We evaluate this situation as a natural result which is compatible with the existing related literature.

Finally, the last title is "Strategic Adaptability". In the data, this title gains its meaning in terms of acting precautiously, preventing strategic blindness and having harmony in both external and internal environments. At this point, we must say that the strategists consider managing risks as the most important step of acting precautiously while making strategic moves. On the other hand, the strategists evaluate the characteristics of the interpersonal relations within the organization and to create a team spirit among employees, in terms of avoiding disharmony in the internal environment and preventing toplevel management's strategic blindness stemming from the conflicts among them.

\section{Table 2: Cultural Values And Attributed Strategic Meanings}

\begin{tabular}{ll} 
Cultural Values & Attributed Strategic Meanings \\
\hline - Honesty & Long-term Sustainability \\
- Trust & \\
- Sincerity & \\
- Positive Reputation & \\
- Partnership Relations & \\
- Quick Decision Making & Strategic Competitive Advantage \\
- Leadership as Guidance & \\
- Adaptability & \\
\hline - Risk Managetitiveness & \\
\hline - Interpersonal Relations & Strategic Deliberateness \\
\hline - Team Spirit & Strategic Blindness \\
\hline
\end{tabular}

We believe that conducting other qualitative and interpretive researches focusing on the relations between cultural values and more specific strategic phenomena and processes like strategy formulation, strategic thinking, strategic alignment or strategy implementation for further efforts on this subject is important. We also believe that developing a "Strategic Values Scale" in the future which will be based on the future knowledge accumulated by further qualitative research efforts focusing on this subject is important and essential. 


\section{REFERENCES}

Ansoff, H. I. (1957). Strategies for Diversification. Harvard Business Review, 35(5), pp. 113-124.

Badr, H. A., Gray, E. R., \& Kedia, B. L. (1982). Personal Values and Managerial Decision Mamking: Evidence from Two Cultures. Management International Review, 22(3), pp. 65-73.

Bamberger, I. (1986). Values and Strategic Behavior. Managent International Review, 26(4), pp. 57-69.

Barney, J. B. (1986). Organizational Culture: Can It Be a Source of Competitive Advantage? Academy of Management Review, 11(3), pp. 656-665.

Berger, P. L., \& Luckmann, T. (1991). The Social Construction of Reality: A Treatise in the Sociology of Knowledge . Penguin Books.

Bettenhausen, K., \& Murnighan, J. K. (1985). The Emergence of Norms in Competitive Decision-Making Groups. Administrative Science Quarterly(30), pp. 350-372.

Bock, A. J., Opsahl, T., George, G., \& Gann, D. M. (2011). The Effects of Culture and Structure on Strategic Flexibility during Business Model Innovation. Journal of Management Studies, 49(2).

Bradley, B. (1998, August). Extrinsic Value. Philosophical Studies: An International Journal for Philosophy in the Analytic Tradition, 91(2), pp. 109-126.

Brink, H. I. (1993). Validity and reliability in qualitative research. Journal of the Democratic Nursing Organisation of South Africa, 16(2), pp. 35-38.

Charmaz, K. (2006). Constructing Grounded Theory: A Practical Guide Through Qualitative Analysis. London: Sage Publications.

Cole, A. (1959). Business Enterprise in Its Social Setting . Cambridge, MA: Harvard University Press.

Erkekoğlu, H., Kılıçarslan, Z., \& Göknar, H. (2014, Temmuz-Aralık). Kayseri İlinin Mobilya Sektörü Rekabet Gücü: Açıklanmış Karşılaştırmalı Üstünlük Endeksi. Erciyes Üniversitesi İktisadi ve İdari Bilimler Fakültesi Dergisi(44), pp. 1-22.

Ertem, M., \& Kılınç, İ. (2017). Culture on Strategic Decision-making: Janissaries and Mercenaries. Electronic Journal of Social Sciences, 17(68), pp. 1337-1373.

Franwick, G. L., Ward, J. C., Hutt, M. D., \& Reingen, P. H. (1994). Evolving Patterns of Organizaitonal Beliefs in the Formation of Strategy. Journal of Marketing, 58(2), pp. 96-110.

Geertz, C. (1973). The Interprtations of Cultures. New York: Basic Books.

Geletkanycz, M. A. (1997). The Salience of Culture's Consequences: The Effects of Cultural Values on Top Executive Commitment to the Status Quo. Strategic Management Journal, 18(8), pp. 615-634.

Giberson, T. R., Resick, C. J., Dickson, M. W., Mitchelson, J. K., Randall, K. R., \& Clark, M. A. (2009). Leadership and Organizational Culture: Linking CEO Characteristics to Cultural Values. J Bus Psychol(24), pp. 123-137.

Goelzer, P. G. (2003). Effects of National Culture on Organizational Culture .

Golden, K. A. (1992, January). The Individual Organizational Strategies for Action in Highly-Ordered Contexts. Journal of Management Studies, 29(1), pp. 1-21.

Guth, W. D., \& Tagiuri, R. (1965). Personal Values and Corporate Strategy. Harvard Business Review.

Hamel, G., \& Prahalad, C. K. (1984). Competing for The Future. Boston: Harvard Business School Press.

Hannan, M., \& Freeman, J. (1977). The Population Ecology of Organizations. American Journal of Sociology(82), pp. 929-964.

Harris, S., \& Ghauri, P. (2000). Strategy formation by business leaders: Exploring the influence of national values. European Journal of Marketing, 34(1/2), pp. 126-142. 
Hedberg, B., \& Jonsson, S. A. (1977). Strategy Formulation as a Discontinous Process. International Studies of Management and Organization, 7(2), pp. 88-109.

Hickson, D., \& Hinnings, C. (1971). Strategic Contingencies Theory of Intraorganizational Power. Administrative Science Quarterly(16), pp. 216-229.

Hofstede, G. (1983). Culture's Consequences: Int. Differences in Work Related Values. London: Oxford University Press Inc. .

Hofstede, G. (1984). Culture's Consequences: Int. Differences in Work-Related Values. SAGE Pub.

Horney, K. (1994). Self-Analysis. Norton Company Inc.

Huo, Y. P., \& McKinley, W. (1992). Nation as a Context for Strategy: The Effects of National Characteristics on Business-Level Strategies. Management International Review, 32(2), pp. 103-113.

Isabella, L. A. (1990). Evolving Interpretations as a Change Unfolds: How Managers Contrue Key Organizational Events. Academy of Management Journal, 33(1), pp. 7-41.

Johnson, G., Scholes, K., \& Whittington, R. (2009). Fundamentals of Strategy. Essex: Pearson Education Limited.

Klenke, K. (2008). Qualitative Research in the Study of Leadership. Emerald Group Pub. Ltd. .

Kroeber, A. L., \& Kluckhohn, C. (1952). Culture: a Critical Review of Concepts and Definitions. By A.L. Kroeber and C. Kluckhohn, with the Assistance of Wayne Untereiner and Appendices by Alfred G. Meyer. The Museum.

Lewis, D. (1996-a). The Organizational Culture Saga - From OD to TQM: A Critical Review of the Literature. Part 1 - Concepts and Early Trends. Leadership and Organization Development Journal, 17(1), pp. 12-19.

Lewis, D. (1996-b). The Organizational Culture Saga - From OD to TQM: a Critical Review of the Literature. Part 1 - Applications. Leadership and Organization Development Journal, 17(2), pp. 9-16.

Lindblom, C. E. (1959). The Science of Muddling Through . Public Administration Review, 19(2), pp. 79 -88 .

Lu, L.-C., Rose, G. M., \& Blodgett, J. G. (1999). The Effects of Cultural Dimensions on Ethical Decision Making in Marketing: An Exploratory Study. Journal of Business Ethics(18), pp. 91-105.

Mantere, S. (2013, June). What Is Organizational Strategy? A Language-Based View. Journal of Management Studies, 50(8), pp. 1-19.

March, J., \& Simon, H. (1958). Organizations. New York: John Wiley.

Martinsons, M. G., \& Westwood, R. I. (1997). Management information systems in the Chinese business culture: An explanatory theory. Information \& Management(32), pp. 215-228.

Miller, D., \& P.H.Friesen. (1980). Momentum and Revolution in Organizational Adaptation. Academy of Management Journal, 4(23), pp. 591-614.

Mintzberg, H. (1979). Patterns In Strategy Formation. International Studies of Management and Organization, 9(3), pp. $67-86$.

Mintzberg, H. (1985, July - September). Of Strategies, Deliberate and Emergent. Strategic Management Journal(6), pp. $257-272$.

Morgan, G. (1986). Images of Organization. SAGE Publications.

Neuman, W. L. (2014). Social Research Methods: Qualitative and Quantitative Approaches. Essex: Pearson Education Limited.

P.F.Drucker. (1985). Innovation and Entrepreneurship: Practice and Principles. Harper\&Row.

Pettigrew, A. M. (1979). On Studying Organizational Cultures. Administrative Science Quarterly, 24(4), pp. 570-581. 
Pfeffer, J., \& Salancik, G. (1978). The External Control of Organizations: A Resource Dependence Perspective. New York: Harper and Row. .

Pitney, W. A., \& Parker, J. (2009). Qualitative Research in Physical Activity and the Healthcare Professions. Human Kinetics.

Porter, M. E. (1998). Competitive Strategy: Techniques for Analyzing Industries and Competitors. New York: The Free Press.

Schein, E. H. (2004). Organizational Culture and Leadership (3 ed.). San Fransisco: Jossey-Bass.

Schumpeter, A. (1934). The Theory of Economic Development. London: Oxford University Press.

Schwartz, S. H., \& Bilsky, W. (1987). Toward a universal psychological structure of human values. Journal of Personality and Social Psychology, 5, pp. 550-562.

Selznick, P. (1957). Leadership in Administration: A Sociological Interpretation. Evanston,IL: Row, Peterson.

Simon, H. A. ( 1957 ). Administrative Behavior: . New York: Macmillan.

Smith, C. G., \& Vecchio, R. P. (1993). Organizational culture and strategic management: issues in the management of strategic change. Journal of Managerial Issues, 5, pp. 53-70.

Strauss, A. L. (2003). Qualitative Analysis for Social Scientists (14. ed.). Cambridge: Cambridge University Press.

Watson, T. J. (2003). Strategists and Strategy-making: Strategic Exchange and the Shaping of Individual Lives and Organizational Futures. Journal of Management Studies, 40(5), pp. 1305-1323.

Weick, K. E. (1979). The Social Psychology of Organizing. Reading, Massachusetts: Addison-Wesley Publishing Company. 